\title{
JOURNAL.RU
}

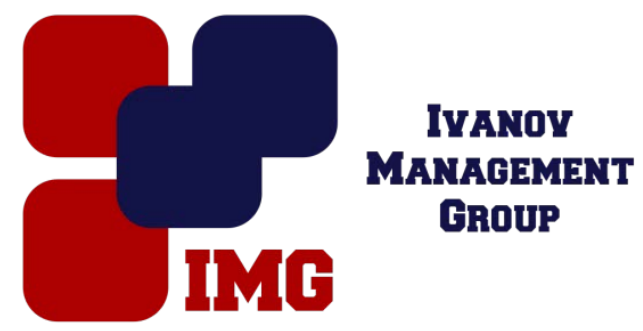

Кисельников И.В.

Алтайский государственный педагогический университет

Барнаул, Россия

doi: 10.18411/lj-28-02-2017-4-04

idsp 000001:lj-28-02-2017-4-04

\section{Типичные ошибки в решении задачи 14 ЕГЭ по математике профильного уровня}

\section{Аннотация}

В статье анализируются типичные ошибки, допущенные участниками ЕГЭ по математике профильного уровня на уровне региона при решении задания 14 в 2016 году.

Ключевые слова: оценка качества образования, средства оценивания результатов обучения, типичная ошибка, методы решения геометрических задач, стереометрия.

В едином государственном экзамене профильного уровня в 2016 году планиметрическая задача (задача 14) содержательно представлена следующими разделами: «Прямые и плоскости в пространстве. Многогранники. Тела и поверхности вращения. Измерение геометрических величин» [2]. Приведем один из примеров стереометрической задачи с развернутым ответом: «В основании четырехугольной пирамиды SABCD лежит прямоугольник ABCD со сторонами $\mathrm{AB}=3$ и ВC $=4$. Длины боковых ребер пирамиды $S A=\sqrt{7}, S B=4$ и $S D=\sqrt{23}$. а) Докажите, что SA - высота пирамиды. б) Найдите угол между прямой SC и плоскостью ASB».

Можно выделить следующий ряд типичных ошибок участников экзамена при выполнении данного задания.

1. Самой распространенной ошибкой при решении задачи 14 в 2016 году была неверная трактовка признака перпендикулярности прямой и плоскости: учащиеся (упрощая себе задачу) считали достаточным доказать перпендикулярность рассматриваемой прямой только одной прямой плоскости для того, чтобы утверждать перпендикулярность прямой и плоскости.

2. Неверное определение искомого угла между прямой и плоскостью (неверный переход к планиметрической задаче) стало также одно из наиболее 
распространенных типовых ошибок при выполнении пункта б) задачи 14 . Процедура определения угла между прямой и плоскостью требует особых рассуждений и дополнительных построений (проекции прямой на плоскость). Однако, многими учащимися искомый угол между прямой и плоскостью был определен интуитивно, без необходимых умозаключений.

3. Распространенным недостатком в решении задачи 14 было отсутствие теоретических ссылок и обоснований логических переходов. Учащиеся не указывают используемую для вывода теорию: определения, теоремы, признаки, свойства и т.д.

Таким образом, на основе анализа типичных ошибок в решениях стереометрической задачи участников ЕГЭ по математике среди причин их появления можно выделить недостаточное владение теоретическим материалом, отсутствие потребности в ссылках на теоретические положения[1].

Для предупреждения выявленных ошибок целесообразно при изучении геометрии в основной и старшей школе требовать от учащихся указания (письменно) и формулировок (устно) используемых аксиом, определений, теорем, свойств, признаков при решении каждой задачи.

\section{Литература}

1. Кисельников И.В. Методический анализ результатов Единого государственного экзамена по математике профильного уровня в 2015 году в Алтайском крае // Современные проблемы науки и образования. - 2015. - № 5. С. 406.

2. Кисельников И.В. Методический анализ веера ответов участников ЕГЭ по математике // Фундаментальные науки и образование : Материалы II международной научнопрактической конференции.- Бийск: ФГБОУ ВПО «АГАО», 2014. С 424-427. 